\title{
Progressive failure analysis of slope water damage based on improved Green-Ampt infiltration model
}

\section{Bin Chen ( 0 873378533@qq.com )}

Chongqing Jiaotong University School of Civil Engineering

\section{Qingyang Ren}

Chongqing Jiaotong University School of Civil Engineering,State Key Laboratory of Bridge and Tunnel

Engineering

\section{Feifei Wang}

Chongqing Jiaotong University School of Civil Engineering

\section{Renkun Zhang}

China Overseas Construction Limited

\section{Beilei Liu}

Chongqing Jiaotong University School of Civil Engineering

\section{Yanping Jia}

Chongqing Jiaotong University School of Civil Engineering

\section{Research Article}

Keywords: Slope engineering, Gravel soil, Green-Ampt model, Slope water damage, Progressive failure

Posted Date: February 19th, 2021

DOI: https://doi.org/10.21203/rs.3.rs-212976/v1

License: (c) (i) This work is licensed under a Creative Commons Attribution 4.0 International License. Read Full License

Version of Record: A version of this preprint was published at Geotechnical and Geological Engineering on April 22nd, 2021. See the published version at https://doi.org/10.1007/s10706-021-01816-w. 


\title{
Progressive failure analysis of slope water damage based on improved Green- Ampt infiltration model
}

\author{
Bin Chen ${ }^{1}$, Qingyang Ren ${ }^{1,2}$, Feifei Wang ${ }^{1}$, Renkun Zhang ${ }^{3}$, Beilei Liu ${ }^{1}$, Yanping Jia ${ }^{1}$ \\ (1.School of Civil Engineering, Chongqing Jiaotong University, Chongqing 400074; 2.State Key Laboratory of \\ Bridge and Tunnel Engineering, Chongqing Jiaotong University, Chongqing 400074; 3. China Overseas \\ Construction Limited, Shenzhen 518053)
}

\begin{abstract}
In order to get the law of rainwater infiltration and the law of progressive water damage, the slope of Tianshang bridge foundation in Yunnan Province is taken as the engineering basis. The site investigation of the damaged slope is carried out, The traditional Green-Ampt model is improved by considering the ponding effect of dynamic water flow on the slope surface. Based on the variation characteristics of wetting front obtained by the improved infiltration model, the progressive failure process of slope with continuous infiltration is simulated by FLAC3D software. The results show that: the water damage of Tianshang bridge slope is mainly caused by the slope absorbing a lot of rainwater in a short time, which has obvious time discontinuity characteristics in time, and shows obvious multi-layer progressive failure characteristics in failure space. The wetting front characteristics obtained by the improved Green-Ampt infiltration model are more consistent with the engineering practice, the water accumulation effect of surface water gradually weakens with the increase of the wet front depth. the slope failure develops gradually from the toe to the top and from shallow to deep, and the intermittent failure characteristics provide surplus time for the engineering treatment, the gravel soil slope should be treated after a small-scale water damage occurs.
\end{abstract}

Key words: Slope engineering; Gravel soil; Green-Ampt model; Slope water damage; Progressive failure

\section{Introduction}

Continuous heavy rainfall is the main cause of slope damage, especially when a large amount of rain is absorbed in a short period of time (Alfonso Gutiérrez-Martín et al. 2019; Damiano E et al. 2017). Due to the characteristics of macroporosity and strong permeability of gravel soil slope, the water damage of the gravel soil slope of mountain roads has become the most widespread form of road geological disasters (Xu et al. 2006; Wang et al. 2015). Therefore, studying the infiltration law and asymptotic failure process of slope rainfall has important theoretical significance and engineering value (Dong, Huang et al 2017; Zhang et al. 2019).

At present, scholars have done a lot of research on the destruction of gravel soil slopes and have achieved rich results (Shen et al. 2011; Chen et al. 2016; Li et al. 2020). Xu et al. (2007) found that the sensitivity of internal friction angle was the highest when studying the factor sensitivity of gravel soil landslide. Liang et al. (2020) analyzed the influence of rainfall intensity, slope angle and vegetation coverage on slope erosion characteristics, and the research showed that rainfall intensity had the most significant influence, followed by vegetation coverage, and slope angle had the least influence. In the aspect of the research on the asymptotic failure of slope, Han et al. (2014) revealed the variation law of stability coefficient in the process of slope asymptotic failure. Hou et al. (2020) proposed a local strength step reduction method for homogeneous slope to analyze the process of slope asymptotic failure. Chen et al. (2020) proposed a domino model to analyze the stability of slope based on the characteristics of slope asymptotic failure. When there is a large amount of rainwater infiltration into the slope, the stability of the slope will be threatened. Therefore, scholars have also carried out a lot of research on slope rainwater infiltration (normbuena Contreras et al. 2012; Jiang et al. 2020). Due to the simple principle, less parameters and convenient use of Green-Ampt infiltration model, it has been widely used in the analysis of rainfall induced failure of slope in recent years (Zhang et al. 2016; 
su et al. 2020). Based on the Green-Ampt infiltration model, Zhang et al. (2020) discussed the evolution law of infiltration slope stability under the condition of no water infiltration and with water infiltration, considering the state of crack propagation. Wei et al (2020) Based on the assumption of saturated-unsaturated layering of loess infiltration, the Green-Ampt model was revised. Pan et al. (2020) established a rainfall infiltration model based on the GreenAmpt model that considers the initial water content of the slope, the groundwater level, and is suitable for different rainfall conditions. The rich research results of the above scholars provide a scientific basis for understanding the infiltration law and failure process of rainwater, and can guide the in-depth study of slope water damage.

Through the analysis of the current research results, it can be found that when using Green-Ampt model to analyze the infiltration of slope rainfall, most scholars think that because the slope is steep, the influence factor of ponding in the traditional Green-Ampt model is ignored. In the research results of considering the ponding in the slope, considering the same thickness of ponding in the slope. Both treatment methods will cause the same depth of rainwater infiltration from the top to the toe of the slope. Dong et al. (2016) carried out the indoor rainfall experiment to study the rainwater infiltration characteristics of gravel soil slope, and found that the rainwater infiltration depth at the toe of slope is the largest after the rainfall. When there is surface water on the slope, the flowing water has a certain gravity head effect relative to the inside of the slope, so the surface water also has the effect of ponding, and from the top to the toe of the slope, the ponding effect is also increasing. In view of this, this paper takes the Tianshang bridge of Zhaotong Qiaojia second-class highway in Yunnan Province of China as the engineering object, fully considers the ponding effect caused by the collection of the flowing water on the slope surface, improves the GreenAmpt infiltration model, and analyzes the progressive failure of the foundation slope of Tianshang bridge by water based on the improved model and FLAC3D numerical simulation software.

\section{Project overview}

\subsection{Engineering geological conditions}

Tianshang Bridge is located on the secondary road from Zhaotong to Qiaojia in Yunnan Province, China. he slope of the bridge foundation is destroyed by long-term rainwater, which endangers the safety of driving, as shown in Figure 1. The bridge is located on the slope of the left bank of the Laodian River. The project area belongs to the landform of high mountains and valleys with structural denudation. The terrain is steep, the slope angle is about 40$45^{\circ}$, and the vegetation is rare. Based on the field investigation results, combined with the survey data during the construction of the bridge, the lithology of the bridge slope can be divided into the following four layers:

(1) Silty clay with gravel: brown yellow, slightly wet, loose, hard plastic state. The content of gravel is about $15 \%-25 \%$, the particle size is mainly $2-3 \mathrm{~cm}$, sub-angular, a small amount of sub-rounded, the rest is silty clay and breccia, the content of silt and clay is more, the thickness is about $0.5-1.1 \mathrm{~m}$.

(2) Colluvial and eluvial gravelly soil: grayish yellow, uneven, slightly dense to moderately dense, slightly wet. The content of gravel is about $60 \%$, the particle size is mainly $3-10 \mathrm{~cm}$, a small amount is more than $10 \mathrm{~cm}$, it is angular, the rest is breccia and a small amount of silty clay, in which the content of silt and clay is less. In shallow seismic reflection method, the velocity of P-wave is $400-800 \mathrm{~m} / \mathrm{s}$ and the thickness is about $7.2-11.5 \mathrm{~m}$.

(3) Strongly weathered Limestone: grayish white, relatively dry, with extremely developed fissures, broken rock mass, poor integrity and low strength. It can be dug with spade and pick and broken by hand. The longitudinal wave velocity is $1200-1800 \mathrm{~m} / \mathrm{s}$, and the thickness is about $7.5-12.9 \mathrm{~m}$.

(4) Moderately weathered limestone: gray-white, thin-medium-thick layered structure, weak weathering, good integrity, well-developed joints and fissures, containing bedrock fissure water, and longitudinal wave speed of 2300$3000 \mathrm{~m} / \mathrm{s}$. 


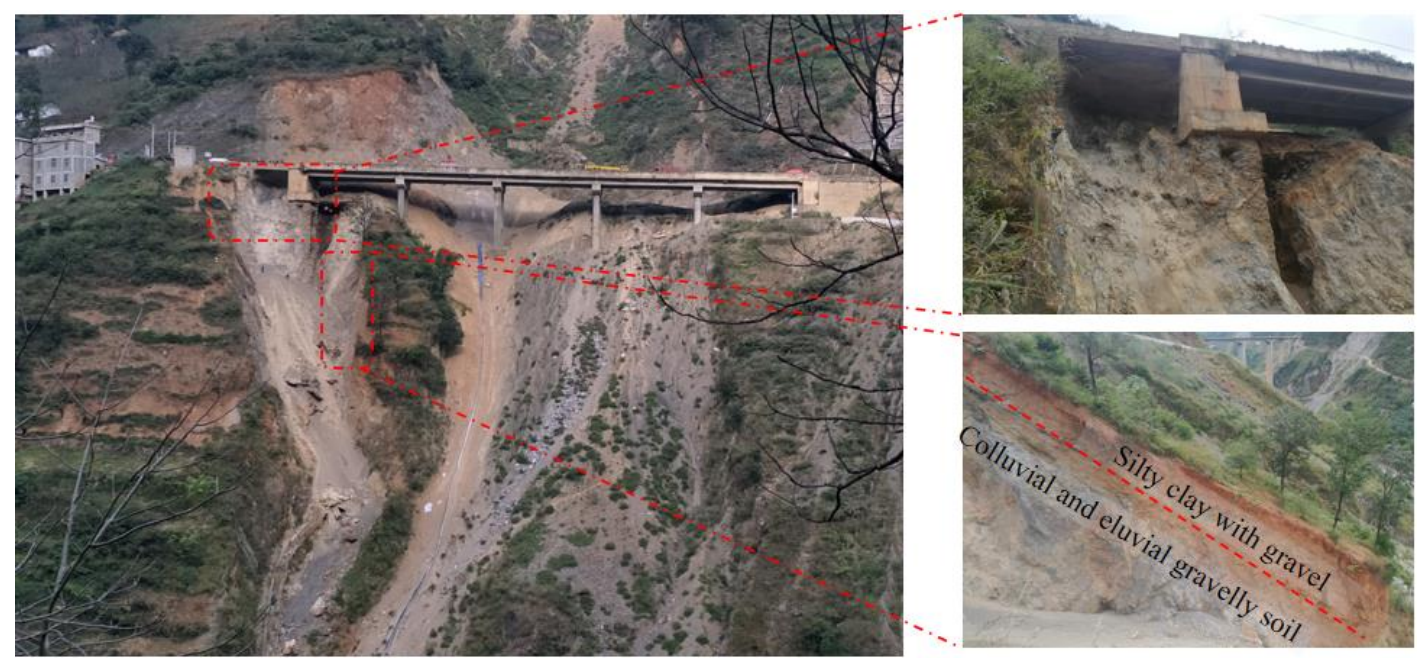

Fig1. Overall and local stratum conditions of water damaged slope

The slope area belongs to the subtropical plateau monsoon climate, the annual rainfall is $1200-1500 \mathrm{~mm}$, and the precipitation period is concentrated in May to October, especially from June to September, accounting for $77 \%$ of the annual rainfall. The Laodian River near the line is the largest body of water. In the rainy season, the fluctuation of the river water has a greater impact on the slope. During the survey period, the Laodian River near the line has a large water volume, and there is a small ditch nearby with small water flow, and no springs are seen at the foot of the slope.

\subsection{Analysis of slope failure situation}

The final damage to the slope of Tianshang Bridge was mainly caused by long-term heavy rainfall and untimely treatment. After the slope damage, a gully with wide upper and narrow bottom was formed (as shown in Figure 2-a), leading to the partial exposure of the pile foundation at the outer side of the abutment and the empty under the approach slab at the bridge head. According to field survey, measurement and statistics, the total length of the gully is about $200 \mathrm{~m}$, the upper edge is $11-26 \mathrm{~m}$ wide, and the widest near the bridge foundation, the bottom side of the gully is $7-18 \mathrm{~m}$ wide, and the gutter depth is $3-11 \mathrm{~m}$. From the perspective of the bottom and walls of the gully, the damaged part of the slope is mainly colluvial and eluvial gravel soil.

The investigation found that, as shown in Figure 2-b, in the lower part of the slope, which accounts for about $1 / 3$ of the total length of the gully, there are many weeds on the left and right walls of the gully. In the middle part of the gully, there are scattered weeds on the middle and upper parts of the gully wall, with the distribution range of about $3 / 5$ of the depth of the gully wall. In the middle and upper parts of the gully, the growth range of weeds is $1 / 3$ $1 / 4$ of the depth of the gully wall, and there is no weeds on the upper part of the gully, this section accounts for about $1 / 4$ of the total length of the gully, and about $2 / 3$ of the lower part of the gully wall is fresh than the upper part. Generally, more weeds grow in the first damaged part of slope than in the second damaged part, and the damage trace of the second damaged part is fresher than that of the first damaged part. Therefore, it can be inferred from the growth of weeds and the freshness of the failure traces of the gully wall that the failure of the slope at the foundation of Tianshang bridge has obvious characteristics of time delay and progressive failure of multi-layer and step-by-step backward. 

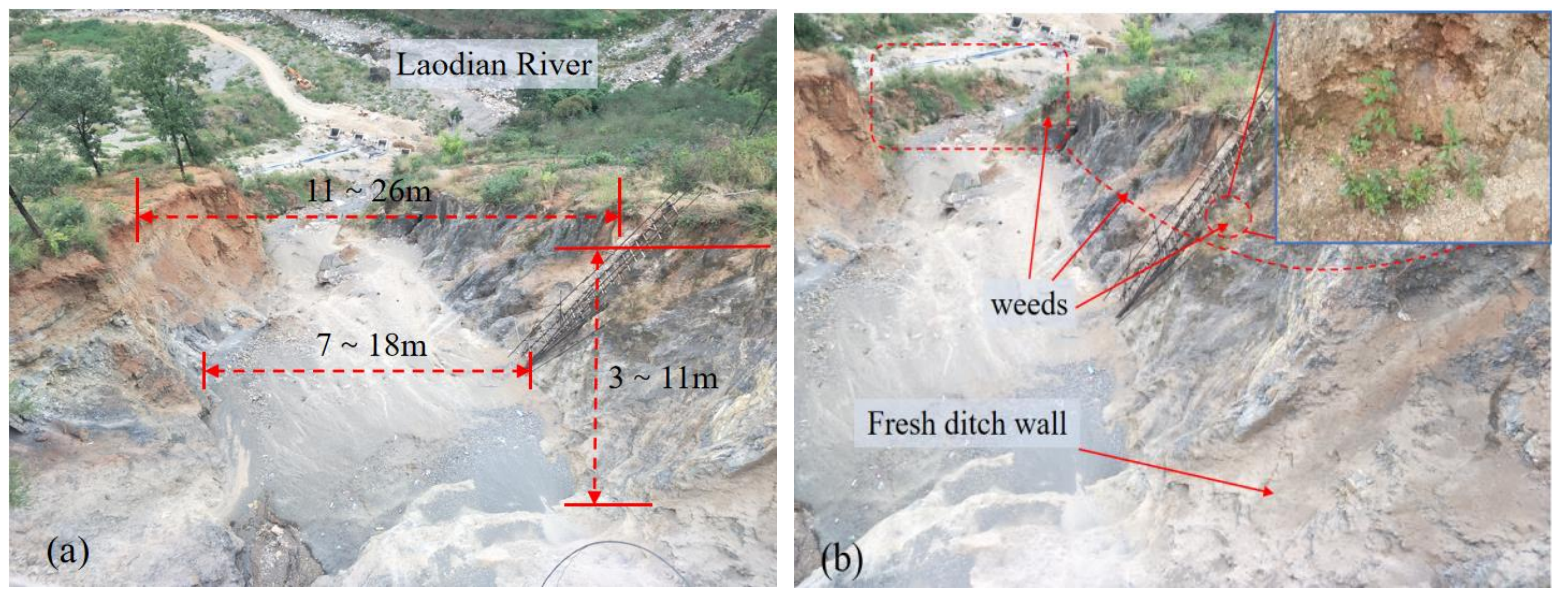

Fig2. Analysis of slope failure

\section{3Analysis of slope failure mechanism}

Since gravel-soil slopes are generally in a stable state under natural conditions (Xu et al. 2006), through the previous analysis of the failure characteristics of the Tianshang Bridge foundation slope, combined with the rock and soil properties of the slope, it can be judged that the continuous heavy rainfall is the main inducing factor of the slope failure. Due to the large porosity of the gravel soil, when the rainfall intensity is low or in the early stage of heavy rainfall, the rainwater infiltrates into the soil. With the extension of the rainfall time, the shallow surface soil of the slope gradually becomes saturated, and the amount of rainwater infiltration is controlled by the saturated permeability coefficient of the soil. Flowing water will be produced on the surface of the slope, there will also be seepage between the soil to the toe of the slope. Therefore, under the action of circulating rainfall, a net-shaped rainwater drainage system is formed inside the slope. Under the effect of long-term seepage in the slope, the fine particles inside the slope are brought to the slope toe to form accumulation, which reduces the drainage capacity of rainwater inside the slope. As a result, the pore water pressure of the soil increases sharply, the effective stress of the soil decreases, and the anti-sliding ability decreases. In addition, the scouring effect of surface rainwater leads to instability at the slope toe. Due to the destruction of the slope toe, the anti-sliding ability of the upper part of the slope is reduced. Under the action of continuous rainfall or the next heavy rainfall, the destruction speed and degree of the slope will increase. The overall failure process mechanism of the slope is shown in Figure 3. Show.

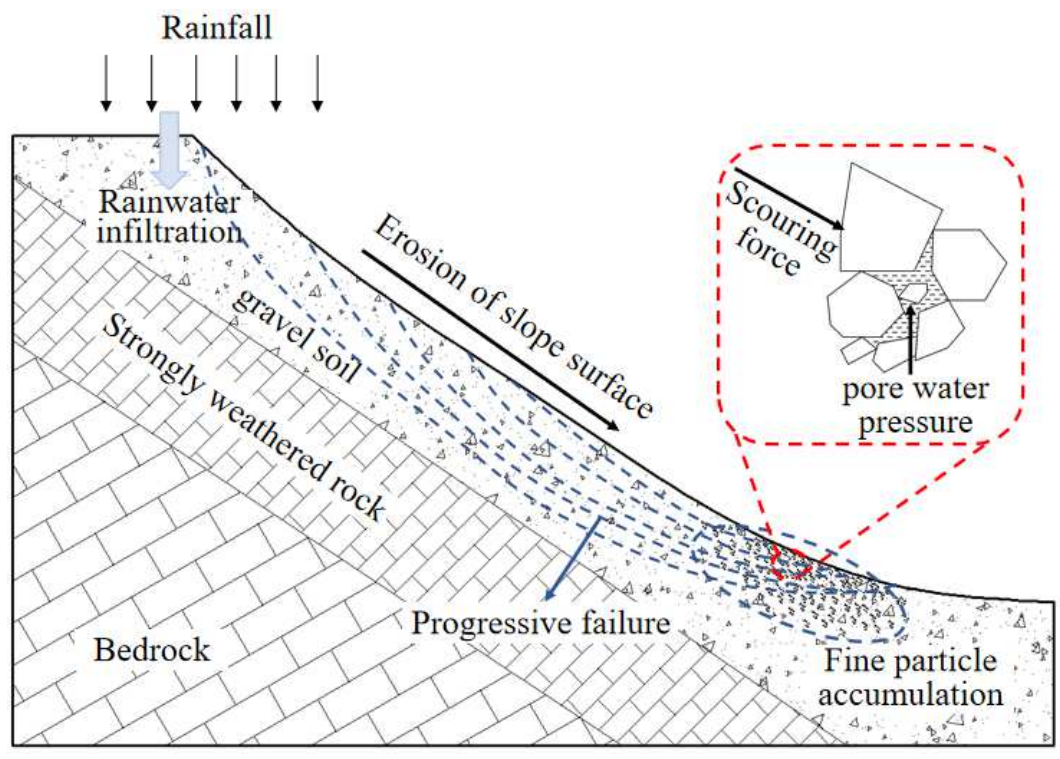

Fig3. Diagram of failure mechanism analysis 


\section{Improvement of infiltration model based on green Ampt}

The traditional Green-Ampt model is an infiltration model based on the infiltration of thin-layered water with uniform soil quality and initial dryness. Its expression is as follows:

$$
i=K_{s}\left(\frac{z_{f}+s_{f}+H}{z_{f}}\right)
$$

In the formula: $i$ is the infiltration rate of rainwater. $K_{s}$ is the saturated permeability of the soil. $z_{f}$ is the depth of the wet peak. $s_{f}$ is the matrix suction at the wet front. $s_{f}$ is the depth of surface ponding. The traditional GreenAmpt model assumes that the ground surface is a horizontal plane, and the wetting front is a completely different interface between wet and dry during the process of rainwater infiltration. Above the wet front is a saturated zone, with a water content of $\theta_{s}$, and the soil below the wet front is a natural soil, the initial moisture content is $\theta_{r}$. Because the slope surface is an inclined plane, some scholars ignore the effect of surface water accumulation when using the Green-Ampt infiltration model. However, although the surface of the inclined slope has no static water accumulation, when the slope produces flowing water, the flowing water also has a squeezing effect against the internal water body of the slope soil. This effect is similar to the static water accumulation on the horizontal surface. The same water pressure will increase the infiltration rate of rainwater on the slope, and the water pressure generated by the slope surface will continue to collect during the downward flow process. When the rainfall is small, all the rainwater is absorbed by the soil, and there is no running water on the slope surface, this effect will disappear. Therefore, according to the amount of rainfall, the slope rainwater infiltration model can be divided into two situations, namely: under normal rainfall, all rainwater is absorbed by the soil, and there is no running water on the surface; under heavy rainfall, running water is produced on the surface. And based on these two situations, make the following basic assumptions:

(1) Similar to the traditional Green-Ampt model, there is an obvious wetting front inside the slope. Above the wetting front is a saturated zone with a water content of $\theta_{s}$, and the soil below the wetting front is a natural soil, with an initial water content of $\theta_{r}$.

(2) Under normal rainfall conditions, the rainfall is less than the saturated permeability of the soil, the rainwater is completely absorbed by the soil, and there is no running water on the surface. In the case of heavy rainfall, there is running water on the surface, and the influence of water on the rainwater infiltration rate is the same as that of static water at the same depth.

(3) The influence of rainwater seepage between saturated soils on the rainwater infiltration rate is ignored.

\subsection{Under normal rainfall}

When the rainfall intensity is low, there is no running water on the slope surface, and the rainwater is absorbed by the soil, so the infiltration rate perpendicular to the normal direction of the slope surface is:

$$
i=q \cos \alpha ; \quad q \cos \alpha \leq K_{S}
$$

In the formula: $q$ is the rainfall intensity, $\alpha$ is the slope angle.

According to the water balance principle of the traditional Green-Ampt model, the slope normal infiltration is equal to the increase in the volumetric water content of the soil in this direction and equal to the rainfall. Therefore, the relationship between the rainfall infiltration, the depth of the moist front, the rainfall intensity and the time can 
be obtained as follows:

$$
I=\left(\theta_{s}-\theta_{r}\right) z_{f}=q t \cos \alpha
$$

Where: $I$ is the cumulative infiltration of rainwater, $t$ is the duration of rainfall.

After finishing formulas (2) and (3), it can be concluded that:

$$
z_{f}=\frac{i}{\theta_{s}-\theta_{r}} t=\frac{q \cos \alpha}{\theta_{s}-\theta_{r}} t ; \quad q \cos \alpha \leq K_{S}
$$

\subsection{Under heavy rainfall}

When the rainfall intensity is high, due to the limited infiltration capacity of the slope, the rainwater cannot fully penetrate into the soil, and the surface of the slope will produce flowing water. The transient phenomenon during the initial rainfall infiltration process is ignored. According to Darcy's law, the infiltration rate at this time is:

$$
i=K_{s}\left(\frac{z_{f} \cos \alpha+s_{f}+H}{z_{f}}\right) ; \quad q \cos \alpha>K_{S}
$$

Due to the continuous collection of surface water, the side surface water flow gradually increases from the slope top watershed downwards. As shown in Figure 4, in order to facilitate the transformation of the formula, it is assumed that the slope surface water flow increases linearly. Therefore, the water depth of the slope surface from the top of the slope can be expressed as:

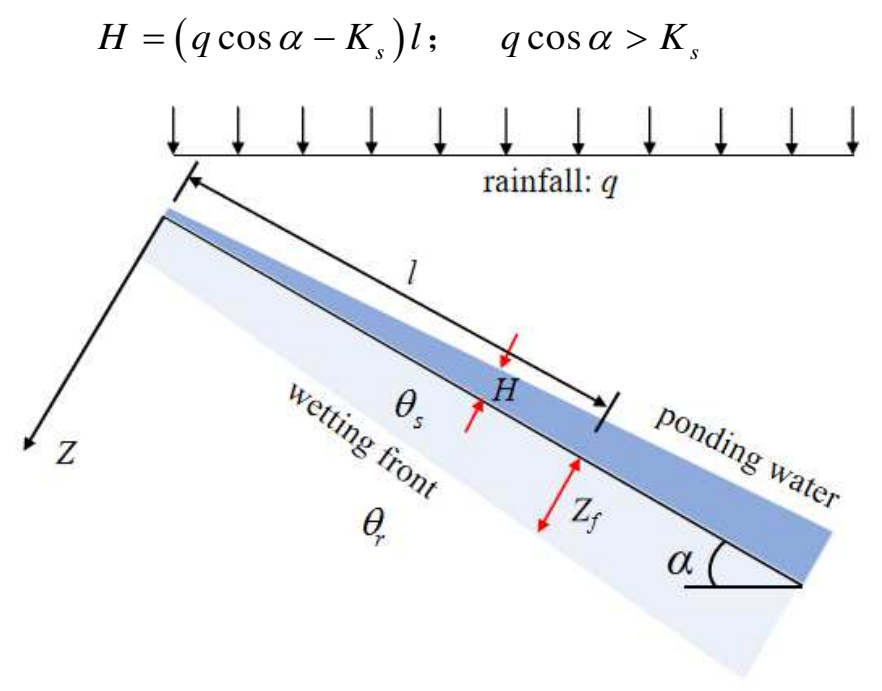

Fig4. Rainwater infiltration model with variable ponding water depth on slope surface

According to the formula (5) and (6), we can get the following results:

$$
i_{l}=K_{s}\left(\frac{z_{f}^{l} \cos \alpha+s_{f}+\left(q \cos \alpha-K_{S}\right) l}{z_{f}^{l}}\right) ; \quad q \cos \alpha>K_{S}
$$

Where: $l$ is the distance between the calculation section and the top of the slope. $i_{l}$ is the infiltration rate of the calculation section, and $z_{f}^{l}$ is the depth of the wetting peak of the calculation section.

According to the infiltration amount at the same section equal to the increase of soil volumetric water content, the following relationship can be obtained: 


$$
i d t=\left(\theta_{s}-\theta_{r}\right) d z_{f}
$$

Substituting formula (7) into formula (8) and integrating, the following formula can be obtained:

$$
t=\frac{\left(\theta_{s}-\theta_{r}\right)}{K_{s} \cos \alpha}\left\{z_{f}^{l}-\left[\frac{\left(q \cos \alpha-K_{s}\right) l+s_{f}}{\cos \alpha}\right] \ln \frac{z_{f}^{l} \cos \alpha+s_{f}+\left(q \cos \alpha-K_{s}\right) l}{\left(q \cos \alpha-K_{s}\right) l+s_{f}}\right\} ; \quad q \cos \alpha>K_{s}
$$

Formula (9) can be used to calculate the wet front depth of the section after $t$ hours under heavy rainfall.

\section{Numerical simulation of asymptotic failure}

\subsection{Analysis of wetting front of Tianshang bridge foundation slope}

The bridge foundation slope of Tianshang Bridge is located at the lower part of the mountain. When there is heavy rainfall, the running water from the upper slope of the bridge will eventually merge into the roadside drainage ditch. Therefore, it is considered that the running water from the upper slope of the bridge does not produce water accumulation on the bridge foundation slope.Therefore, the abutment position of the bridge can be regarded as the top point of rainwater infiltration calculation of the bridge foundation slope. According to the field investigation, the depth of the gully is mainly in the gravel soil layer. Therefore, when analyzing the rainwater infiltration, it is considered that the rainwater only infiltrates in the gravel soil layer. Due to the small thickness of silty clay with gravel in the surface layer of slope, the surface soil is considered as colluvial and eluvial gravelly soil in the calculation of wetting front depth and numerical modeling analysis. According to the values of similar projects, the saturated permeability of the soil $K_{s}=0.007 \mathrm{~mm} / \mathrm{s}$, the matrix suction at the wet front $s_{f}=100 \mathrm{~mm}$, the saturated water content is $\theta_{s}=0.42$, and the initial water content is $\theta_{r}=0.1$. According to the rainfall monitoring in the project area, rainfall The strength is $q=50 \mathrm{~mm} / \mathrm{h}$, the slope length is $200 \mathrm{~m}$, and the slope angle is $\alpha=42{ }^{\circ}$. According to formula (9), the variation law of wetting front depth of Tianshang bridge foundation slope after rainfall lasting for 1, $5,10,15,20,25$ and 30 hours is shown in Figure 5.

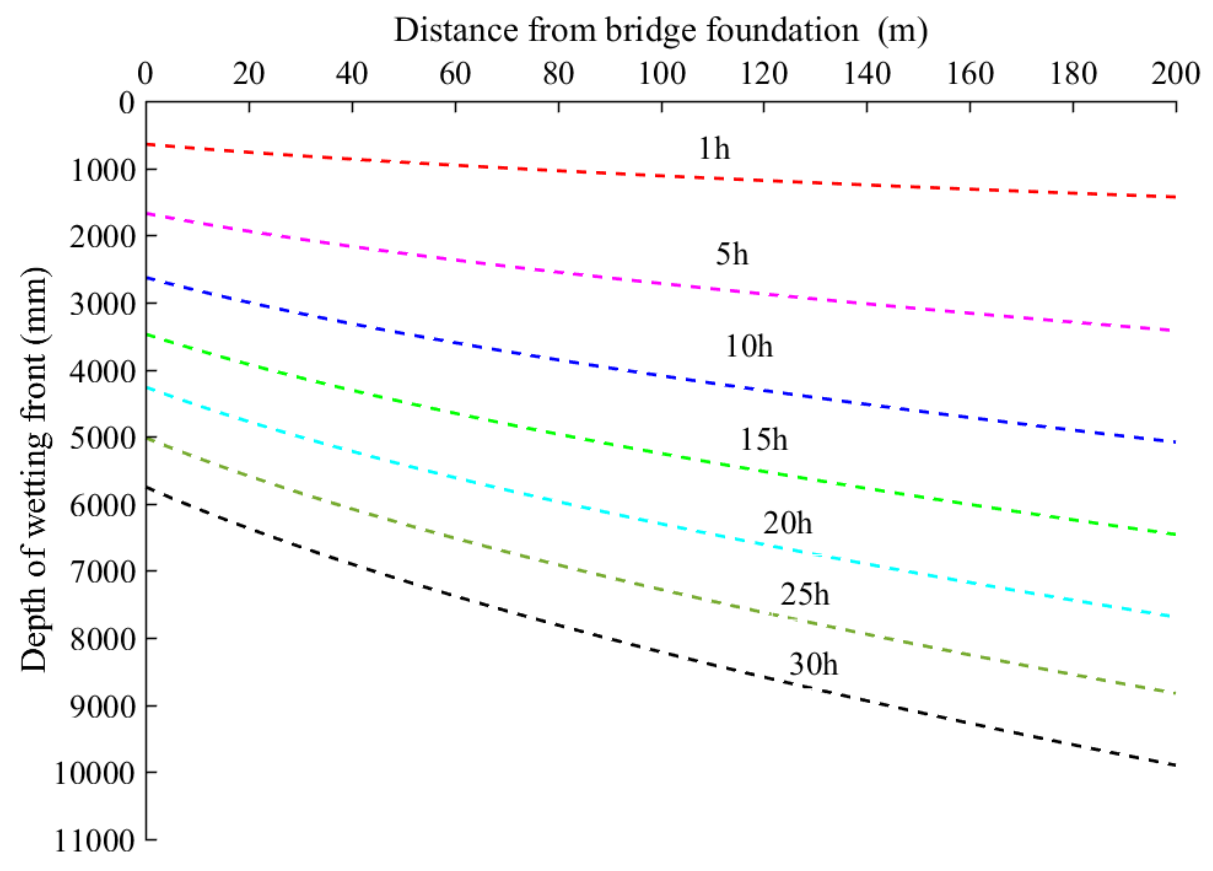

Fig5. Variation of wetting front depth of Tianshang bridge foundation slope 
It can be seen from Figure 5 that the infiltration rate of rainwater on the slope at the beginning of rainfall is relatively fast. As time goes on, the infiltration rate slows down, the infiltration amount in the first hour accounts for about $13 \%$ of the total infiltration amount in 30 hours.From the top of the slope (the position of the bridge foundation), the farther away from the top of the slope, the greater the depth of rainwater infiltration, this phenomenon is similar to the test results of Dong et al (2016) and Su et al (2015). In the same period, the infiltration amount of rainwater in the lower part of the slope is larger than that in the upper part of the slope, and this difference gradually decreases with the continuation of rainfall time. Indicating that with the increase of the depth of the wetting front, the ponding effect of surface water gradually weakens, and the infiltration rate of the slope is mainly controlled by the properties of the soil itself.

\subsection{Numerical simulation analysis}

The model is built according to the actual project size, the top of the slope is taken to the position of the bridge foundation, the foot of the slope is taken to the bank of the Laodian River, the slope length is $200 \mathrm{~m}$, and the slope angle is $42^{\circ}$. Because the slope damage is mainly caused by heavy rainfall and the bridge foundation is embedded in the middle weathered layer, the influence of the bridge foundation on the slope water damage is ignored in the numerical simulation. In order to truly simulate the failure process of slope, the samples of colluvial and eluvial gravelly soil were collected during field investigation. The physical and mechanical parameters of colluvial and eluvial gravelly soil were obtained through laboratory test, as shown in Table 1. The physical and mechanical parameters of strongly weathered limestone and moderately weathered limestone were obtained according to similar projects.

Table 1 Physical and mechanical parameters of rock and soil

\begin{tabular}{ccccccc}
\hline Name & State & $\begin{array}{c}\text { Density } \\
\left(\mathrm{Kg} / \mathrm{m}^{3}\right)\end{array}$ & $\begin{array}{c}\text { Elastic } \\
\text { Modulus } \\
(\mathrm{Mpa})\end{array}$ & $\begin{array}{c}\text { Poisson's } \\
\text { ratio }\end{array}$ & $\begin{array}{c}\text { Cohesion } \\
(\mathrm{Kpa})\end{array}$ & $\begin{array}{c}\text { Internal } \\
\text { friction angle } \\
(\mathrm{9})\end{array}$ \\
\hline $\begin{array}{c}\text { Colluvial and eluvial } \\
\text { gravelly soil }\end{array}$ & Natural & 1850 & 120 & 0.26 & 30 & 38 \\
$\begin{array}{c}\text { Strongly weathered } \\
\text { limestone }\end{array}$ & Saturated & 2000 & 80 & 0.32 & 25 & 29 \\
$\begin{array}{c}\text { Moderately weathered } \\
\text { limestone }\end{array}$ & Natural & 2100 & 500 & 0.25 & 200 & 39 \\
\hline
\end{tabular}

Based on the variation law of wetting front depth in each period obtained in Section 4.1, the variation of plastic zone and the maximum shear stress increment in the slope are calculated by FLAC3D software, as shown in Fig. 6 and 7.

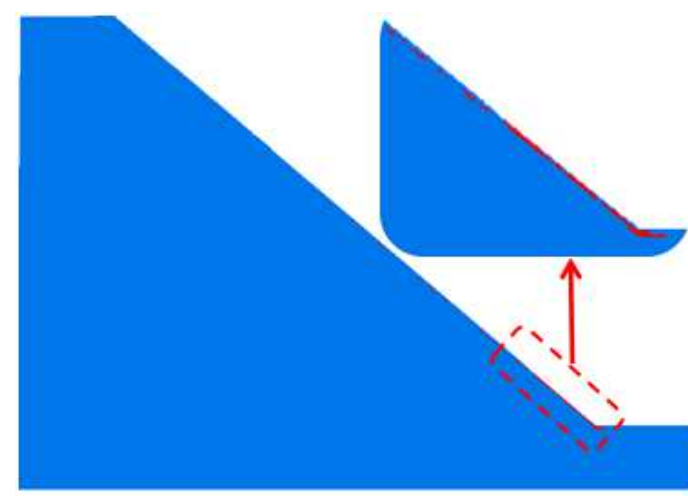

(a) $1 \mathrm{~h}$

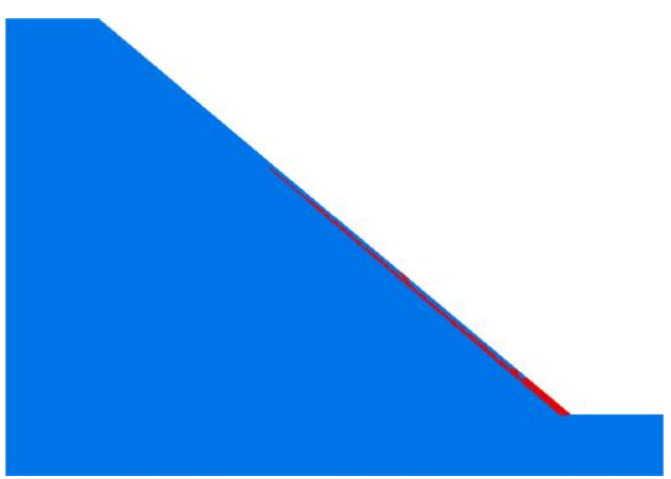

(b) $5 \mathrm{~h}$ 


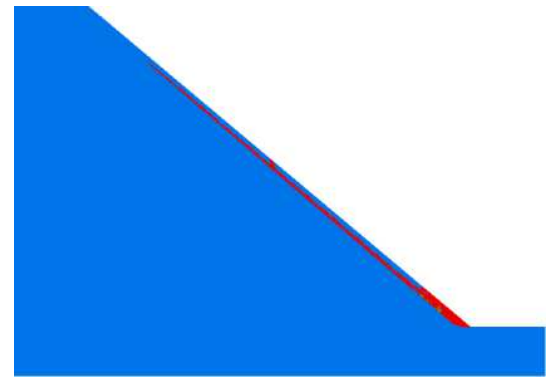

(c) $10 \mathrm{~h}$

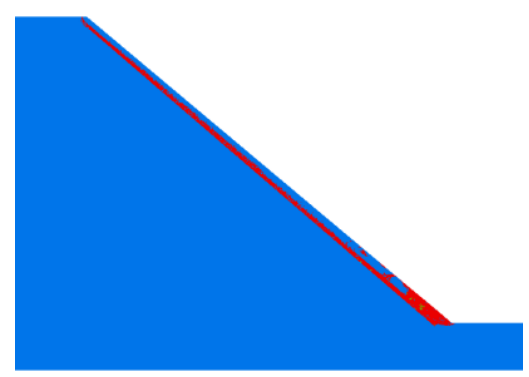

(d) $20 \mathrm{~h}$

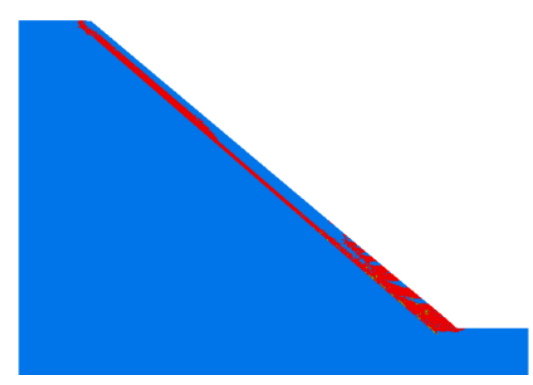

(e) $30 \mathrm{~h}$

Fig6. Changes of plastic zone with rainwater infiltration

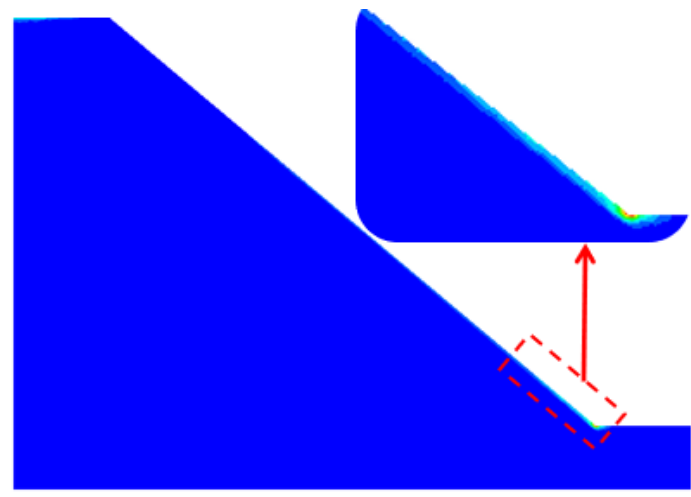

(a) $1 \mathrm{~h}$

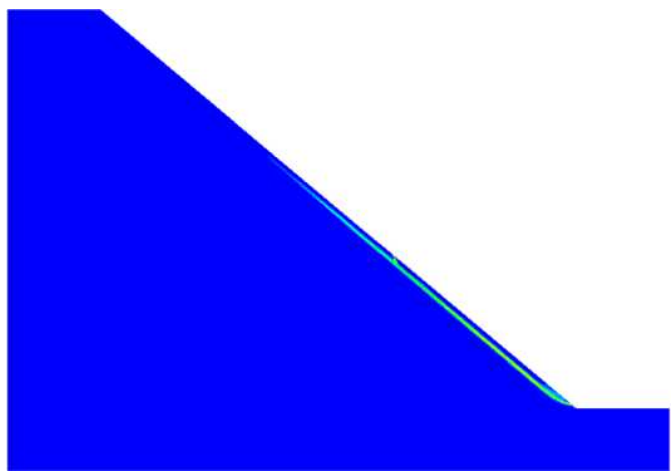

(b) $5 \mathrm{~h}$

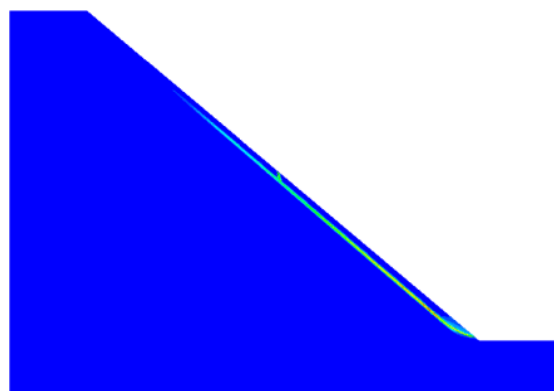

(c) $10 \mathrm{~h}$

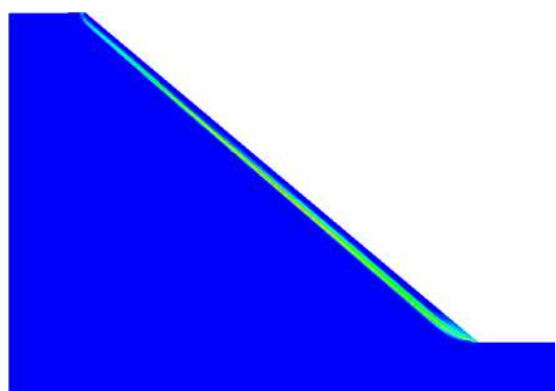

(d) $20 \mathrm{~h}$

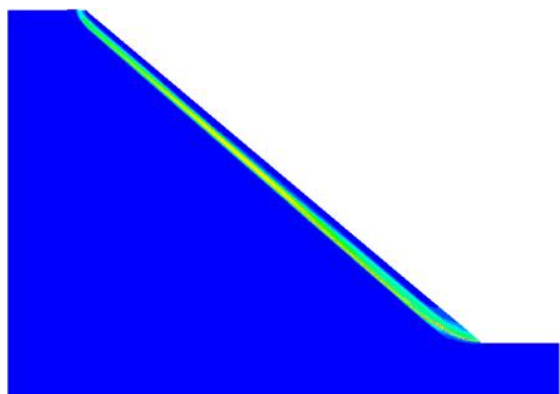

(e) $30 \mathrm{~h}$

Fig7. Changes of maximum shear strain increment

It can be seen from figures 6 and 7 that the slope is still stable as a whole after the rainfall lasts for 1 hour. Local small-scale damage occurs at the foot of the slope. Within $1 / 3$ of the shallow surface of the lower part of the slope, the plastic zone is sporadically distributed. Due to the small depth of the wetting front at the upper part of the slope, there is no plastic zone in this part. When the rainfall lasts for 5 hours, the plastic zone in the slope develops upward from the toe to a position about $1 / 3$ times the slope length from the top of the slope, and penetrates to the surface of the slope at a position 1/3 times the slope length from the toe. According to the distribution nephogram of the plastic zone and the maximum shear stress distribution nephogram, it can be seen that after 5 hours of rain, the shallow surface gravel soil $1 / 3$ times the length of the lower slope has been destroyed by water. When the rainfall lasts for 10 hours, the plastic zone of the slope extends to a position 1/4 times the length of the slope top, and the damage range of the slope also develops to a position 1/2 times the length of the slope top, and the damage depth is longer than 5 hours. Big. After the rain lasted for 20 hours, the damage range of the slope had developed on the top of the slope. After 30 hours, the damage depth of the slope continued to increase due to the continuous infiltration of rainwater. Summarizing the aforementioned change characteristics, it can be seen that the slope damage gradually develops from the foot of the slope to the top of the slope, from shallow to deep, and the water damage of the slope generally 
shows the characteristics of multi-level progressive retreat as the rainfall continues.

Since the calculation of the wet front depth and numerical simulation in this paper use continuous heavy rainfall, in engineering practice, it is rare to achieve such a large rainfall in such a short period of time. Therefore, the water damage of the slope in the actual project will show obvious time discontinuity. It is this characteristic that also provides surplus time for the treatment of the project. Therefore, when a small area of water damage occurs on the gravel soil slope It should be treated when it is destroyed.

\section{Conclusion}

In order to obtain the water damage characteristics of gravel soil slopes and the characteristics of rainwater infiltration, with Yunnan Tianshang Bridge as the engineering background, through field investigation of the slope failure characteristics. based on the traditional Green-Ampt infiltration model and considering the ponding effect of surface water, the green Ampt model is improved. And based on the improved model combined with FLAC3D numerical simulation software, the failure characteristics of the slope with the infiltration of rainwater are analyzed. The main conclusions are as follows:

(1) The final damage to the slope of Tianshang Bridge is mainly caused by long-term heavy rainfall and untimely treatment. Each damage to the slope is mainly caused by the slope absorbing a large amount of rain in a short time.

(2) The water-damaged damage of the Tianshang Bridge slope has obvious temporal discontinuity in time, and the interval of each damage is gradually reduced. In the damage space, it shows obvious characteristics of multi-layer progressive damage.

(3) The wet front characteristics obtained by the improved Green-Ampt rainfall infiltration model considering the water accumulation effect of the surface water are more consistent with the actual project. In the same period, the rainfall infiltration volume of the lower part of the slope is greater than that of the upper part of the slope. This gap gradually decreases with the continuation of rainfall, indicating that as the depth of the wet front increases, the water accumulation effect of surface water gradually weakens.

(4) After the rainfall lasted for 1 hour, the slope as a whole was still stable. After 5 hours, water damage occurred in the lower part of the slope within $1 / 3$ of the slope length. After 10 hours, the damage was expanded to $1 / 2$ of the slope. At 20 hours, the damage range develops to the full slope length. With the infiltration of rainwater, the damage depth increases each time, the slope damage characteristics obtained by simulation are the same as those obtained by field investigation and analysis, both show obvious asymptoticity.

(5) The intermittent failure characteristics of the slope provide surplus time for the treatment of the project. The gravel-soil slope should be treated after a small-scale water damage occurs.

\section{Acknowledgements}

Thanks for the technical support provided by the School of Civil Engineering and the State Key Laboratory of Chongqing Jiaotong University, and thank China Overseas Construction Co., Ltd. for their assistance in obtaining the engineering materials of the Tianshang Bridge in Yunnan.

\section{Author Contributions}

Chen Bin completed the improvement of the Green-Ampt model and the writing of the article, Ren Qingyang directed the research content of this article, Wang Feifei and Liu Beilei completed part of the data processing work, Jia Yanping participated in the project site survey work, and Zhang Renkun obtained the site data Provided help. 


\section{Founding}

National Natural Science Foundation of China (41472262); Innovative research group of Chongqing University (cxqt19021); Key project of Chongqing Natural Science Foundation (cstc2020jcyj-zdxmx0012); The first batch of Chongqing outstanding talents innovation and leading talent project (cqyc201903026); The graduate scientific research and innovation project of Chongqing Jiaotong University (2020b0002).

\section{Compliance with ethical standards}

Conflict of interest: The authors declare no conflict of interest.

\section{References}

Alfonso Gutiérrez-Martín, Miguel Ángel Herrada, José Ignacio Yenes, et al. Development and validation of the terrain stability model for assessing landslide instability during heavy rain infiltration[J]. Natural Hazards and Earth System Sciences, 2019, 19(4):721736.

Damiano E, Greco R, Guida A, et al. Investigation on rainwater infiltration into layered shallow covers in pyroclastic soils and its effect on slope stability[J]. Engineering Geology, 2017, 220:208-218.

$\mathrm{Xu}$ jiancong, Shang Yuequan. Influence of permeability of gravel soil on debris landslide stability [J]. Journal of rock mechanics and engineering, 2006 (11): 2264-2271

Wang Shuang, Li Xiaochun, Wang Shaoquan, et al. Study of gravel soil granation characteristics influence on the permeability coefficient [J]. Journal of rock mechanics and engineering, 2015 (S2): 4394-4402.

Dong Hui, Huang Runqiu, Gao Qian-Feng. Rainfall infiltration performance and its relation to mesoscopic structural properties of a gravelly soil slope[J]. Engineering Geology. 2017, 230:1-10.

Dong Hui, Huang Runqiu, Luo Xiao, et al. Spatial distribution and variability of infiltration characteristics for shallow slope of gravel soil [J]. Chinese Journal of Geotechnical Engineering, 2017, 39(008):1501-1509.

Zhang Kunyong, Li Guangshan, Du Wei, et al. Simulation of progressive failure process of soil slope[J]. Journal of Tianjin University, 2019, 52(0z1):99-105.

Shen Shuijin, Sun Hongyue, Shang Yuequan, et al. Scouring-penetration coupling analysis of embankment slope under rainfall action[J]. Chinese Journal of Rock Mechanics and Engineering, 2011, 30(12): 2456-2462.

Chen Zhichao, Luo Xuan, Liu Kan, et al. Seepage characteristics and mitigation measures of a gravel soil landslide [J]. Rock and Soil Mechanics, 2016, 37(03): 813-818+849.

Zhuomin Li, Xianqi Luo, Jinfeng Bi, et al. Numerical modelling of internal erosion process in gravel soils based on the percolation analytical method. 2020, 79(14):1-15.

Xu Jiancong, Shang Yuequan. Sensitivity analysis of influencing factors of debris landslide [J]. Rock and Soil Mechanics, 2007, 28(010):2046-2051.

Liang Zhishui, Liu Haowei, Zhao Yanbing, et al. Effects of rainfall intensity, slope angle, and vegetation coverage on the erosion characteristics of Pisha sandstone slopes under simulated rainfall conditions[J]. Environmental Science and Pollution Research, 2020,27:17458-17467

Han Liu, Shu jisen, Zhou Wei, et al. Mechanical mechanism and slope stability analysis in progressive failure process [J]. Journal of Huazhong University of science and Technology (NATURAL SCIENCE EDITION), 2014 (8): 128-132

Hou Shiwei, Ma Shihe, Li Hongnan, Zhang Hao. Research on progressive slope failure based on local stepwise reduction method of local strength[J]. Journal of Disaster Prevention and Mitigation Engineering, 2020, 40(01): 72-78. 
Chen Wensheng, Jiang Maolin, Dai Jianing, Ding Bo, Yin pingbao. A Domino Model Based Slope Stability Analysis Method [J]. Chinese Journal of geotechnical engineering, 2021,43 (01): 112-120

Norambuena-Contreras J , Arbat G, P.J. García Nieto, et al. Nonlinear numerical simulation of rainwater infiltration through road embankments by FEM[J]. Applied Mathematics \& Computation, 2012, 219(4):1843-1852.

Jiang Shuihua, Liu Xian, Huang Faming, et al. Failure mechanism and reliability analysis of soil slopes under rainfall infiltration considering spatial variability of multiple soil parameters [J]. Chinese Journal of Geotechnical Engineering, 2020, 42(05): 900907.

Zhang Jie, Lu Te, Xue Jianfeng, et al. Modified Green-Ampt model for analyzing rainfall infiltration in slopes [J]. Rock and Soil Mechanics, 2016, 37(09): 2451-2457.

$\mathrm{Su}$ Yonghua, Li Chengcheng. Slope stability analysis based on Green-Ampt infiltration model under intermittent heavy rainfall[J]. Journal of Hunan University (Natural Science Edition), 2020, 47(03): 28-36.

Zhang Jian, Zhu David, Zhang Shihua. Shallow slope stability evolution during rainwater infiltration considering soil cracking state[J]. Computers and Geotechnics, 2020, 117:1-12

Wenxin Hu, Zhiping Zhang, Xun Chai, et al. Modified infiltration model for saturated-unsaturated loess based on Green-Ampt model and its parametric study [J]. Rock and Soil Mechanics, 2020, 41(06): 1991 -2000.

Pan Yongliang, Jian Wenxing, Li Linjun,et al. A study on the rainfall infiltration of granite residual soil slope with an improved GreenAmpt model [J]. Rock and Soil Mechanics, 2020, 41(08): 2685-2692.

Dong Hui, Li Zhifei, Jiang Xiuzi, et al. Indoor model test of gravel soil slope under heavy rainfall[J]. Journal of Safety and Environment, 2016, 16(004):236-241.

Su Hongjian, Liu Zizhen, Huang Zhihua, Huang Bin. A model test investigation on infiltration depth of soil slope under sustained rainfall [J]. Chinese scientific paper, 2015,10 (01): 91-94 


\section{Figures}

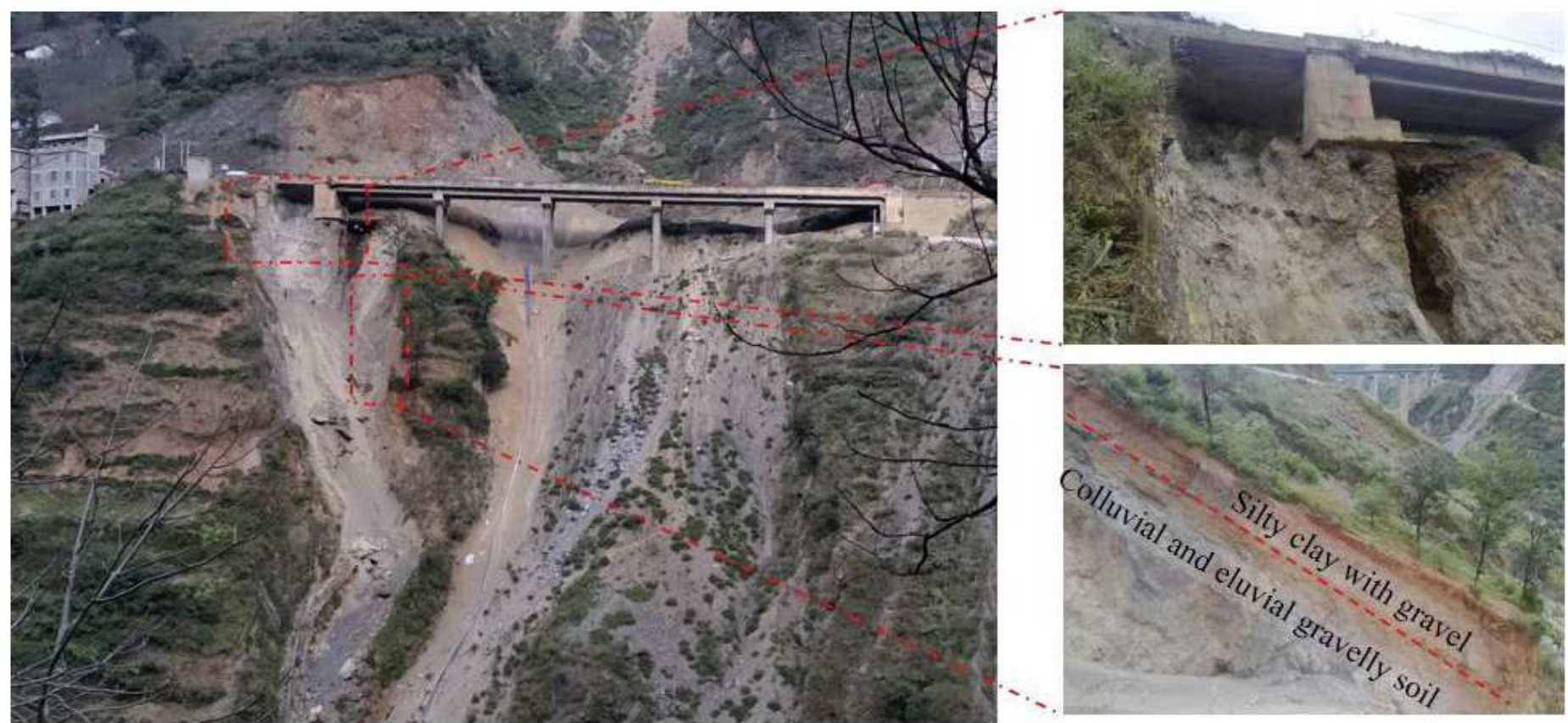

\section{Figure 1}

Overall and local stratum conditions of water damaged slope
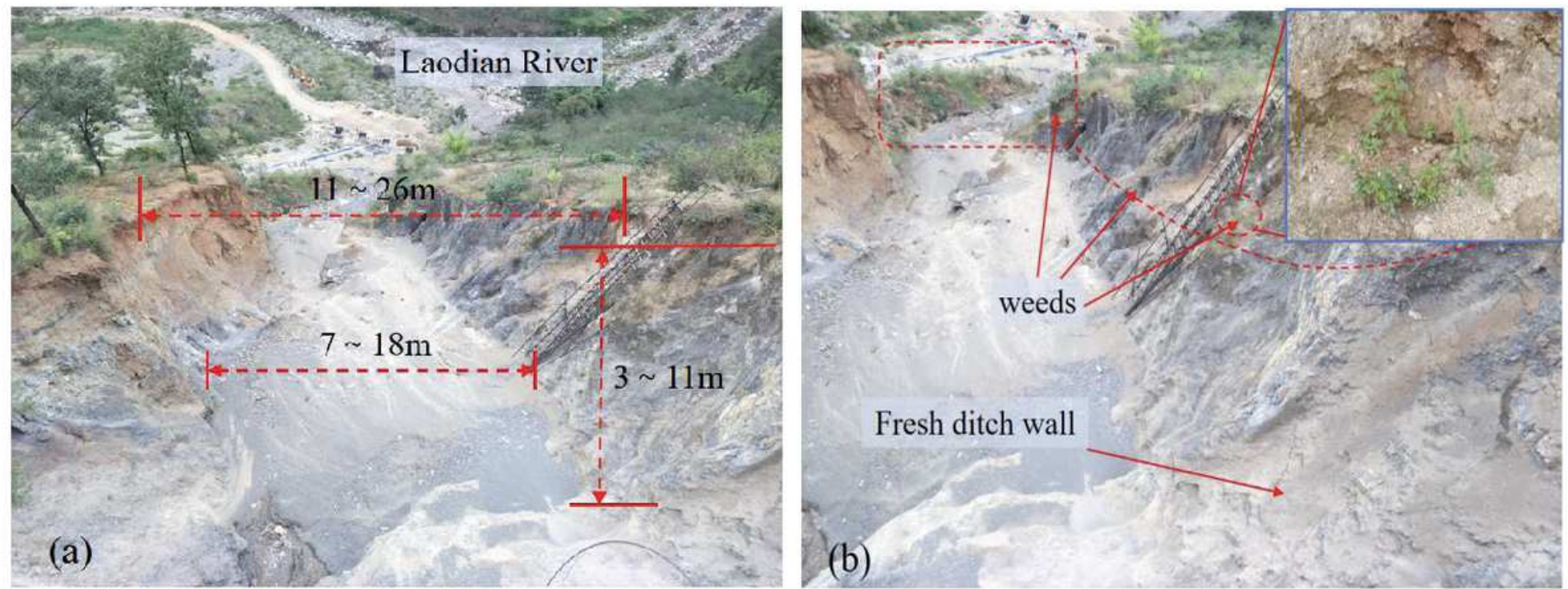

\section{Figure 2}

Analysis of slope failure 


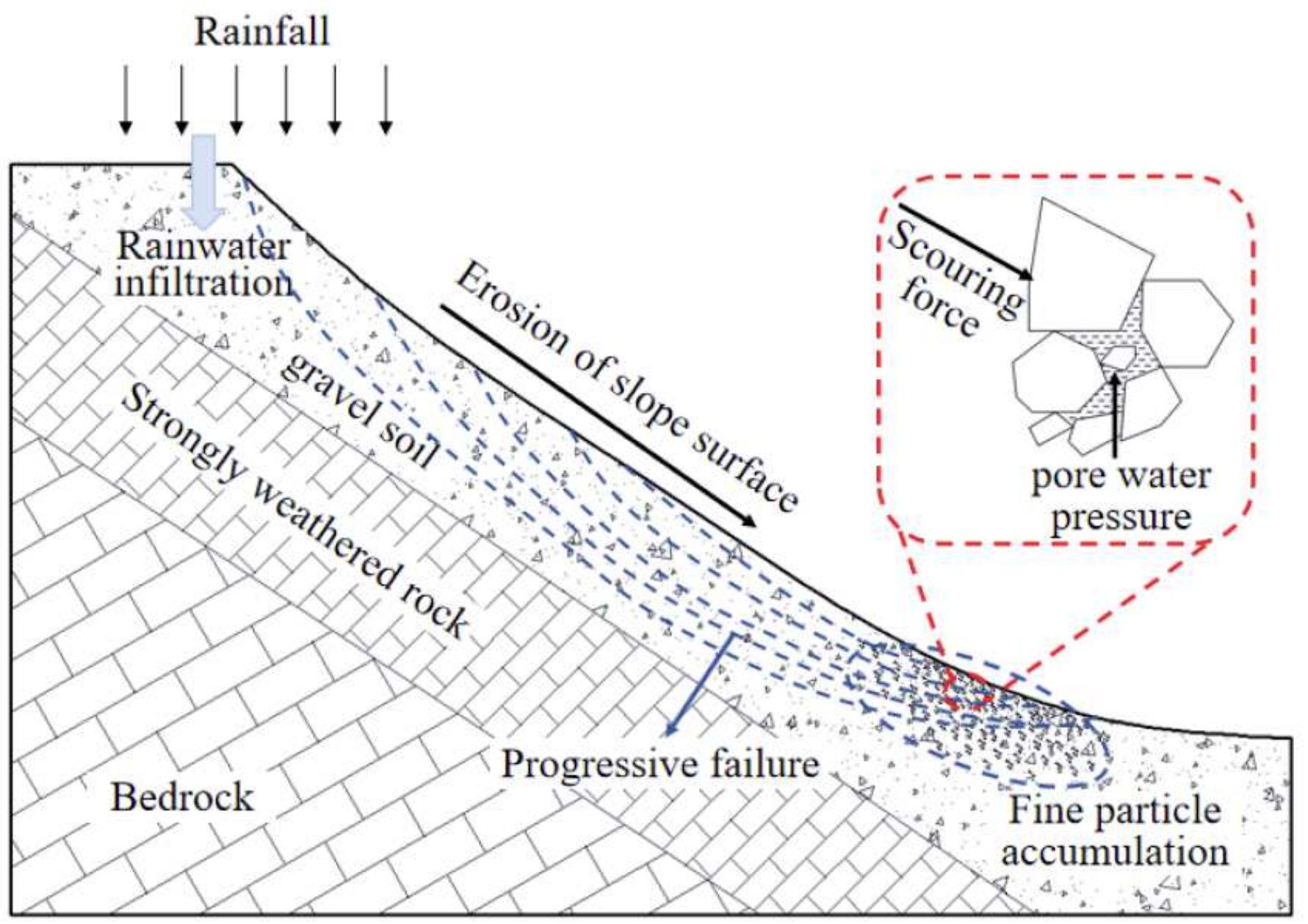

Figure 3

Diagram of failure mechanism analysis

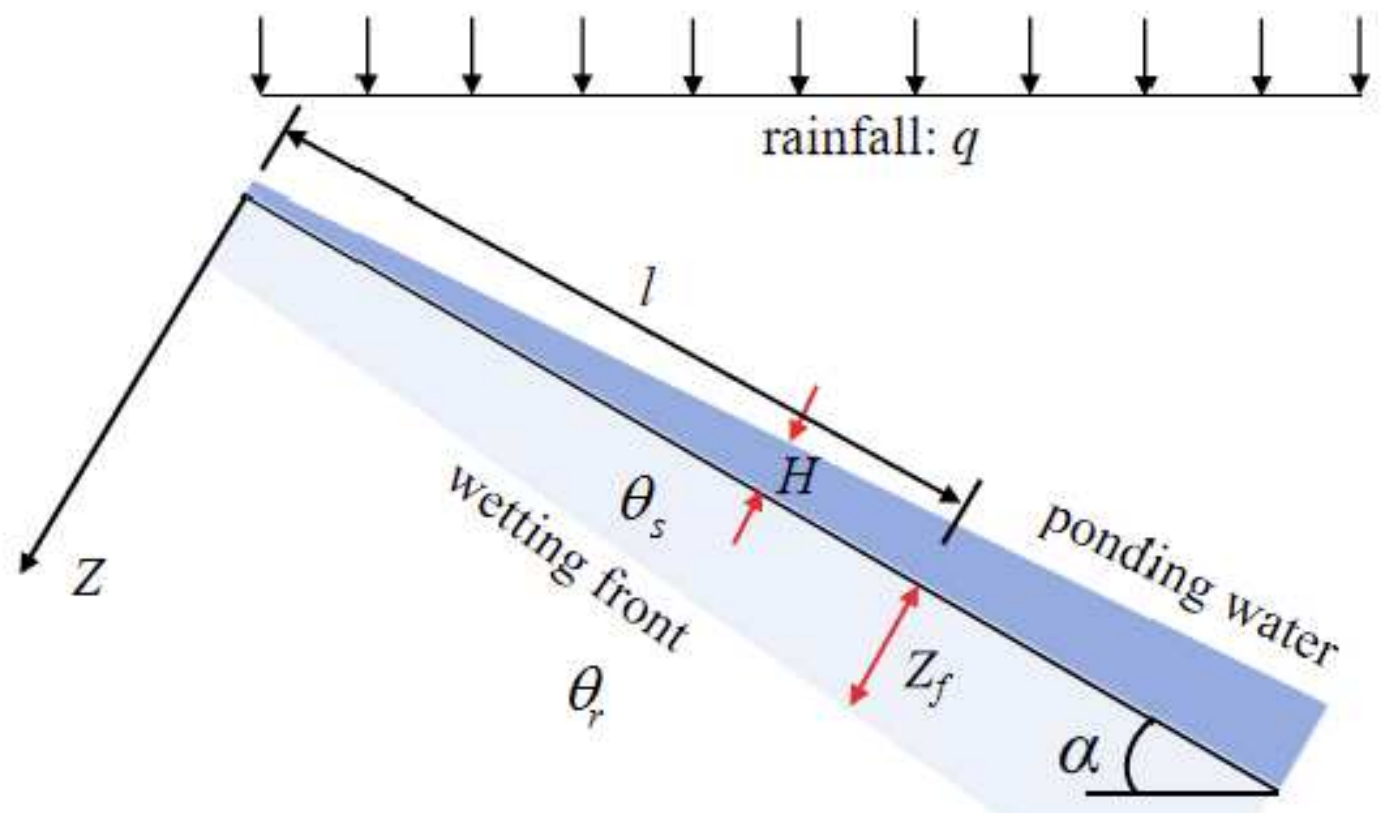


Figure 4

Rainwater infiltration model with variable ponding water depth on slope surface

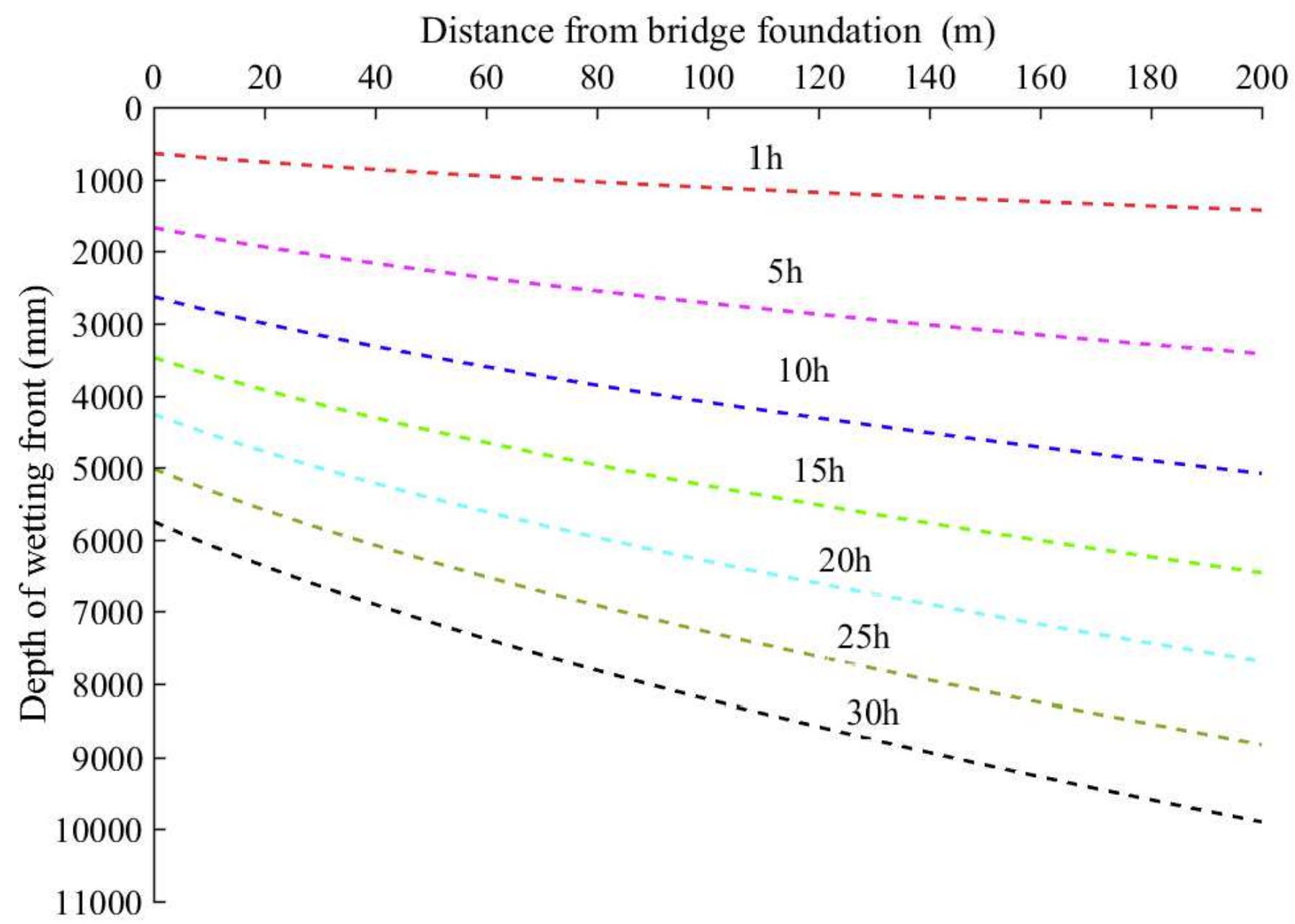

\section{Figure 5}

Variation of wetting front depth of Tianshang bridge foundation slope 


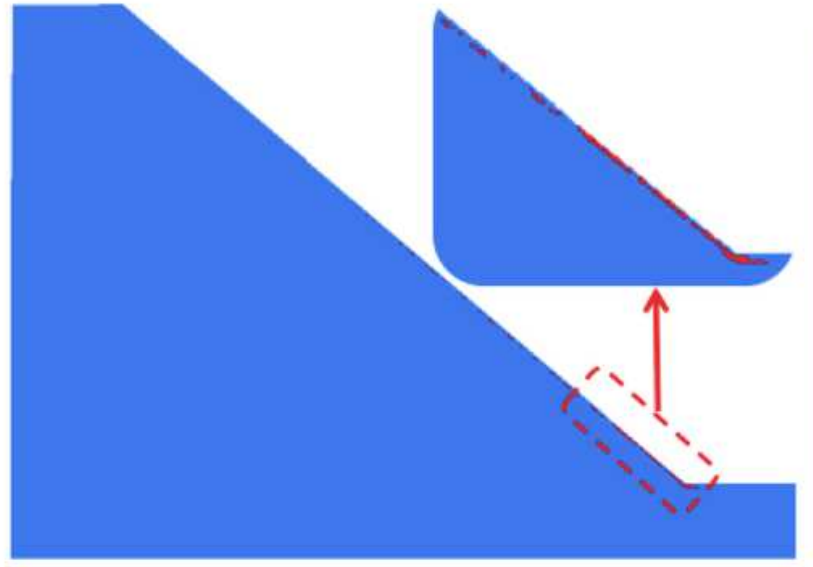

(a) $1 \mathrm{~h}$

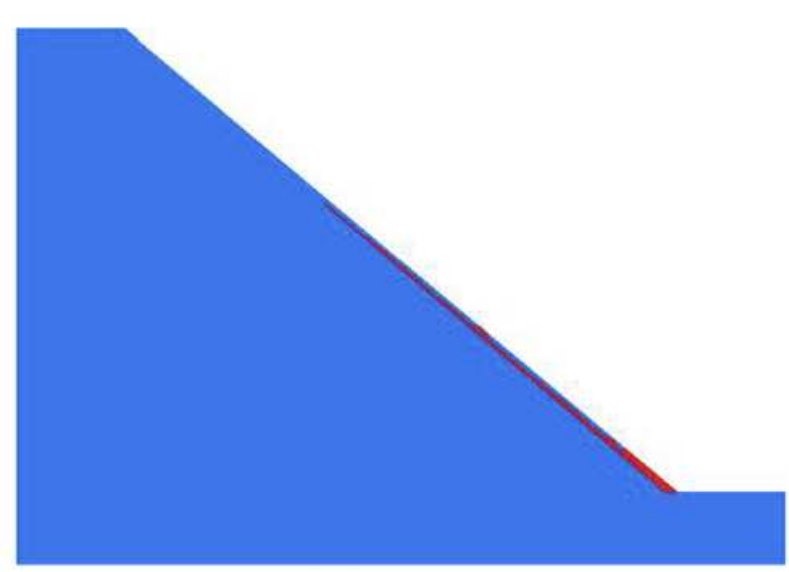

(b) $5 \mathrm{~h}$

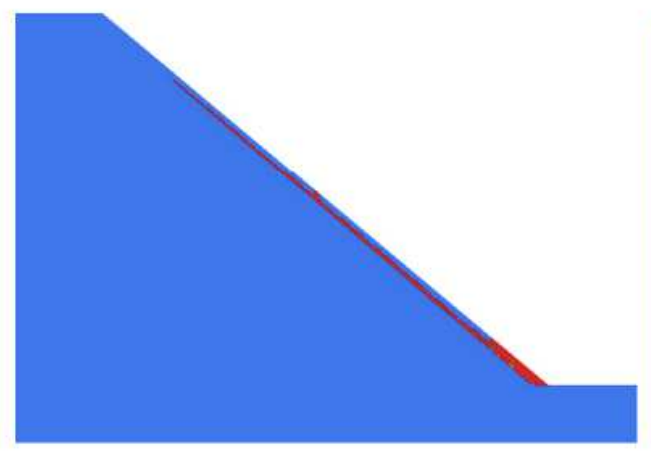

(c) $10 \mathrm{~h}$



(d) $20 \mathrm{~h}$

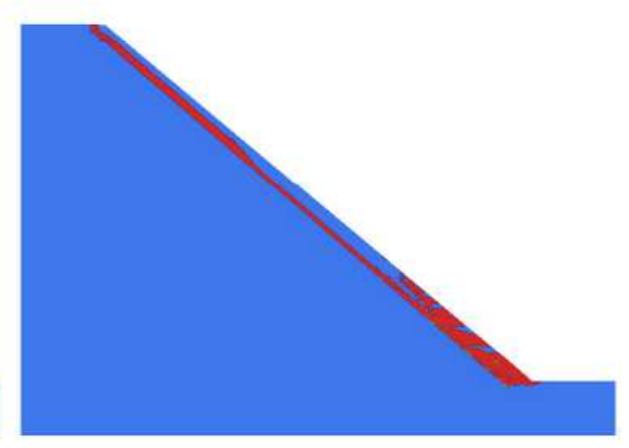

(e) $30 \mathrm{~h}$

Figure 6

Changes of plastic zone with rainwater infiltration 


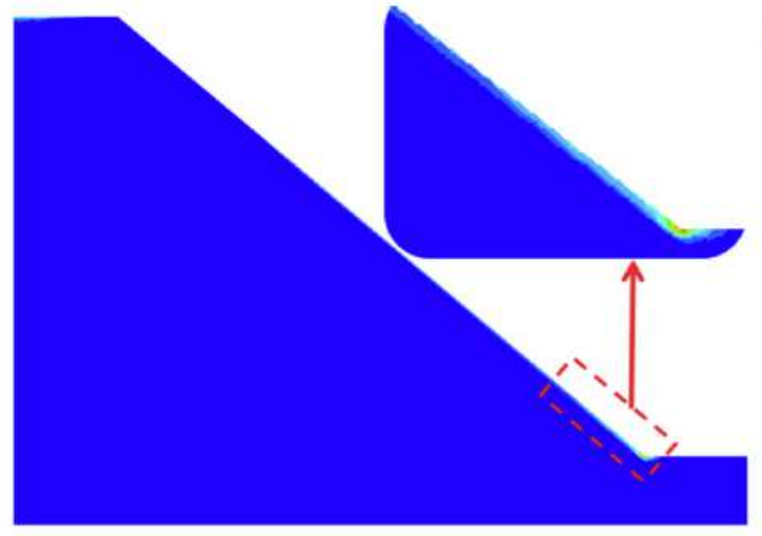

(a) $1 \mathrm{~h}$

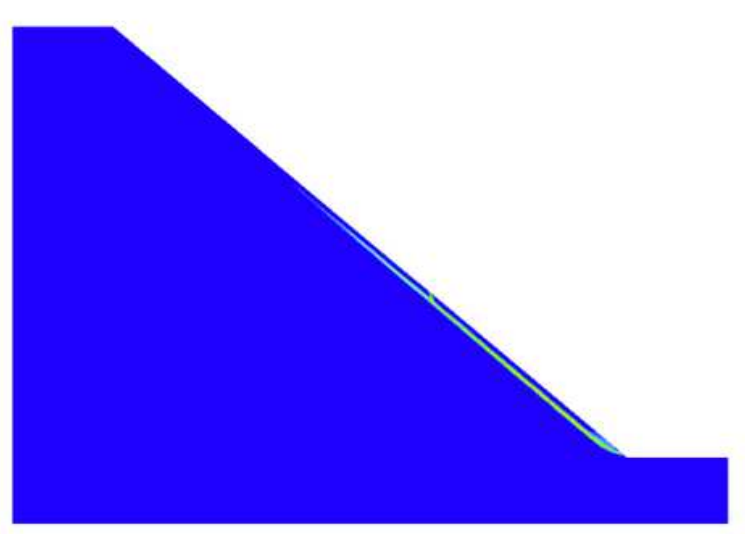

(b) $5 \mathrm{~h}$

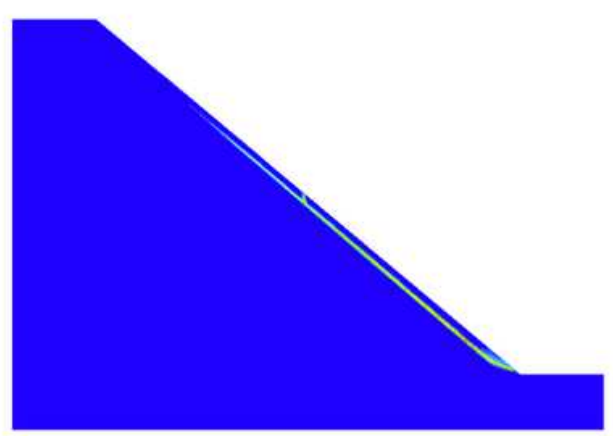

(c) $10 \mathrm{~h}$

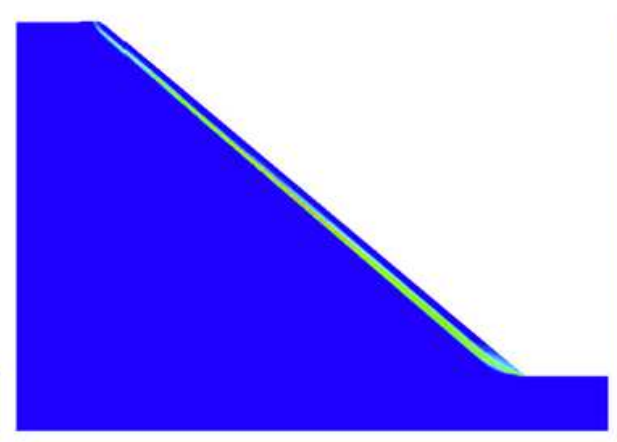

(d) $20 \mathrm{~h}$

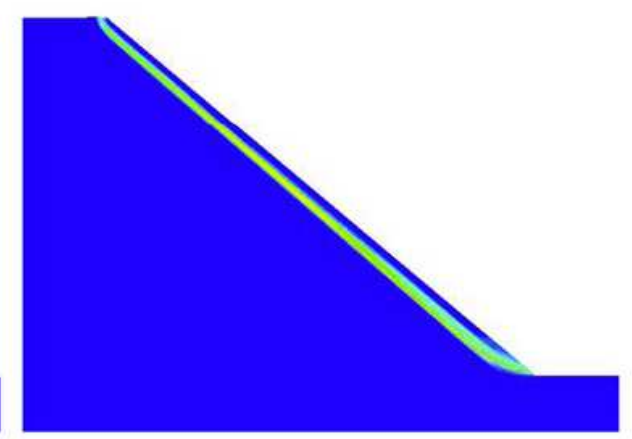

(e) $30 \mathrm{~h}$

Figure 7

Changes of maximum shear strain increment 